\title{
Listas Nominais de Trabalhadores: escravos e livres na construção de pontes e estradas na província de Minas Gerais (1830-1880)
}

\author{
Télio Cravo*
}

\begin{abstract}
Este artigo apresenta os resultados preliminares da exploração das listas nominais de trabalhadores empregados na construção de pontes e estradas na província de Minas Gerais. Enfatizam-se a ocupação e a condição social, bem como o sistema de aluguel de escravos. No século XIX, Minas Gerais ocupou posição proeminente no cenário nacional, notadamente por seu dinamismo demográfico e econômico, com taxa de crescimento populacional superior à média do Brasil e o maior sistema escravista do país. Nessa comunicação são arrolados resultados concernentes a 3.300 registros nominais.
\end{abstract}

Palavras-Chave: Estrutura ocupacional. Livres e escravos. Listas nominais. Trabalhadores. Minas Gerais.

\footnotetext{
* Núcleo de Pesquisa em História Econômica e Demográfica (NPHED/Cedeplar), Universidade Federal de Minas Gerais (UFMG), Belo Horizonte-MG, Brasil; Universidade Federal de São Paulo (Unifesp), São Paulo-SP, Brasil (teliocravo@yahoo. com.br; https://orcid.org/0000-0002-0907-7800).
} 


\section{Introdução}

Este artigo visa divulgar os resultados parciais, resultantes de projeto de pesquisa vinculado ao Núcleo de Pesquisa em História Econômica e Demográfica (NPHED) do Centro de Desenvolvimento e Planejamento Regional (Cedeplar) da Universidade Federal de Minas Gerais (UFMG). ${ }^{1}$ Entre 2004 e 2018, a pesquisa voltou-se para coleta, codificação e montagem de Banco de Dados dos Processos de Construção de Estradas e Pontes de Minas Gerais (BARBOSA, 2011; BARBOSA; GODOY, 2008; BARBOSA; GODOY, 2014). ${ }^{2}$ Valendo-se desta base de dados, o presente trabalho traz os resultados preliminares da exploração das Listas Nominais de Trabalhadores. ${ }^{3}$

As Listas Nominais de Trabalhadores permitem adentrar o mundo do trabalho e identificar: nome do trabalhador, pelo qual se deduz o sexo; ofício exercido (ocupação); remuneração diária; número de dias de trabalho; condição social dos trabalhadores; origem/ procedência; nome do proprietário escravista; e vencimento mensal.

As Listas Nominais de Trabalhadores, cuja documentação coeva denominava de "folhas de ferias", ${ }^{4}$ referiam-se ao mês de trabalho nas obras públicas viárias. Elas eram oriundas da prestação de contas de particulares responsáveis pelas obras (arrematantes e congêneres), ou produzidas por engenheiros nomeados para administração.

O objetivo geral é investigar a economia e a sociedade do trabalho, com a finalidade de compreender sua história, tomando como dimensão da análise a relação dinâmica entre composição laboral, relações escravistas, inserção de homens livres no mercado de trabalho (KLEIN; LUNA, 2009; KLEIN, 1969), estrutura ocupacional e o sistema de aluguel de escravos (LIBBY, 1988; MELLO; SLENES, 1980). Apresentam-se os resultados da relação entre estrutura ocupacional e condição social, tendo como base 3.300 registros nominais de trabalhadores entre as décadas de 1830 e 1880.

Este artigo busca contribuir para a compreensão da relação entre transporte e trabalho no século XIX. É consenso historiográfico que as obras férreas colaboraram diretamente para que engenheiros nacionais encontrassem ocupação (NAGAMINI, 1994; TELLES, 1994;

\footnotetext{
${ }_{1}^{1}$ Este trabalho origina-se de pesquisa mais abrangente que vem sendo desenvolvida junto ao Núcleo de Pesquisa em História Econômica e Demográfica (NPHED/Cedeplar) referente aos Processos de Pontes e Estradas em Banco de Dados, composto por 24.000 documentos para o período de 1840-1889.

${ }^{2}$ Pesquisa desenvolvida com financiamento concedido pela Fundação de Apoio à Pesquisa do Estado de São Paulo (Fapesp), processo n. 2014/06264-2, e Coordenação de Pessoal de Nível Superior (Capes).

${ }^{3}$ Numa primeira etapa foi necessária a compilação dos processos construtivos de pontes e estradas por meio de planilhas, cuja formatação permitiu o recolhimento das seguintes informações: identificação da caixa e número do documento; identificação do processo da obra pública; número de páginas; nome da localidade e status administrativo; data; nome e função pública do autor e do destinatário; e sinopse do documento. Em 2004, iniciou-se o cotejamento das informações. A coleta das mesmas se prolongou até 2008, quando concluída a etapa de levantamento, catalogação. Em 2009, foi criado o Banco de Dados de Estradas e Pontes e iniciada a codificação. 0 desenvolvimento da base é coordenado pelo professor Marcelo Magalhães Godoy. 0 recolhimento de dados no Arquivo Público Mineiro foi realizado pelos bolsistas de iniciação científica Elaine Costa Aguiar, Wanessa Ferreira de Souza, Phillipe Scherrer Mendes e Télio A. Cravo.

${ }^{4} \mathrm{O}$ termo "folha de ferias" dialoga com práticas do século XIX: a do trabalho a "jornal", que, segundo Luiz Maria da Silva Pinto (1832, p. 640), em seu dicionário, corresponde ao "que se dá pelo trabalho de um dia ao jornaleiro"; e também ao sentido empregado ao termo "feria", que significa o "jornal dos que trabalham pela semana" (PINTO, 1832, p. 513).
} 
CARVALHO, 2002), além do fato de que as ferrovias empregaram milhares de trabalhadores braçais de distintas categorias jurídicas (LAMOUNIER, 2012, p. 23-47; SILVA, 1976) - livres, escravizados, libertos, imigrantes e coolies chineses (SOUZA, 2013). Apesar destas contribuições, há poucas menções sobre trabalhadores nas construções de pontes e estradas (CRAVO; CONTERNO; GODOY, 2020).

Pretende-se descrever o universo documental, sua finalidade e etapas de elaboração, além de procurar conhecer a história da fonte. É preciso realçar que as Listas Nominais de Trabalhadores possuem limitações e traduzem um recorte da realidade, que envolve o modo de elaboração, por quem e para quem, além dos motivos para a sua confecção. Estas informações auxiliam diretamente na compreensão do documento, bem como no entendimento de suas sub-representações.

\section{Fonte: Listas Nominais de Trabalhadores}

As Listas Nominais de Trabalhadores de construções de pontes e estradas expressam uma visão de mundo e possuem uma finalidade. Por isso, a crítica documental direciona especial atenção ao fato de que elas foram produzidas por pessoas que tinham preocupações, preconceitos, valores e compromissos específicos.

A fase inicial de execução das obras viárias exigia a participação de engenheiros para elaboração de projetos e orçamentos. Em seguida, com base no projeto e orçamento, as obras eram colocadas em hasta pública, por via de editais públicos para arrematação. Durante o período em hasta pública, engenheiros prestavam esclarecimentos aos licitantes, munidos de plantas, orçamentos, tabelas de aterros, desaterros e declividades (CRAVO, 2016; BARBOSA, 2011).

Realizada a arrematação e selecionada a proposta, assinava-se o contrato. 0 arrematante deveria apresentar fiadores residentes na província ou depositar em condições hipotecárias apólices ou joias. A partir de então, iniciava-se a contagem de tempo para a conclusão das obras (CRAVO, 2016).

0 pagamento de cada parcela era condicionado pela lista nominal de trabalhadores e os recibos de pagamentos. Efetivava-se o pagamento após o exame das obras, realizado in loco pelos engenheiros, que emitiam parecer, ou, em outros casos, por autoridades locais (juiz de paz, delegado, subdelegado, pároco e comissões nomeadas pelo presidente de província) (Regulamento n. 53, 1866, Art. 1ํe 9ํํ). 0 objetivo era julgar as contas, aprová-las e liberar o montante em réis destinado. ${ }^{5}$

As obras viárias exigiram a contratação de trabalhadores braçais ou qualificados. As listas nominais revelam o ajustamento de livres e a disseminação do sistema de aluguel de escravos (Regulamento n. 53, Art. 42º, 1866; Regulamento n. 68, Art. 58ํㅜ 1873).

\footnotetext{
${ }^{5}$ Art. 24ํㅡ e 25을 Regulamento n. 68 de 1873. Ouro Preto: Typ. J. Francisco de Paula Castro, 1874, t. 40, part. 2, p. 1-18.; Art. $36^{\circ}$ e $38^{\circ}$ Regulamento n. 53 de 1866. Ouro Preto: Typ. J. Francisco de Paula Castro, 1867, t. 32, part. 2, p. 29-40.
} 


\section{Resultados preliminares e discussão das fontes}

A pesquisa identificou e recolheu subsídios de 23 Listas Nominais de Trabalhadores, que compreendem 14 obras viárias (1835-1887). ${ }^{6}$ Levando em conta a regionalização da província de Minas Gerais, indicada no Mapa 1 (GODOY, 1996), essas listas abrangem territórios e regiões diversos. É necessário apontar que os registros nominais de trabalhadores concentram-se nas regiões Mineradora Central Oeste, Mata, Sudeste, Sul Central e Intermediária de Pitangui-Tamanduá. ${ }^{7}$ As cinco regiões respondem por $96,8 \%$ dos registros nominais, sendo que o restante dos registros refere-se à região denominada Sertão, conforme mostra a Tabela 1. A concentração em cinco regiões reitera o argumento de Barbosa e Godoy (2014) sobre a forte associação entre o nível alto de desenvolvimento ${ }^{8}$ das regiões mineiras e a incidência das obras públicas, o que indica desequilíbrio entre as regiões na distribuição dos recursos financeiros destinados à infraestrutura e, em especial, a importância não apenas da centralidade política da Mineradora Central Oeste, mas também da fiscalidade ${ }^{9}$ e da dinâmica das atividades agroexportadoras da Mata mineira (BARBOSA; GODOY, 2014, p. 484-485).

\footnotetext{
${ }^{6}$ Listas Nominais de Trabalhadores das seguintes obras viárias: Estrada de Juiz de Fora a Barbacena (1872-1873); Estrada de Lavrinhas (1841); Estrada do Paraibuna (1843-1844); Estrada entre Mariana e São Caetano (1845); Estrada de São Sebastião a São Caetano (1845); Estrada de São Caetano para Furquim (1845); Estrada em direção a Queluz (1835); Estrada de Campanha a Santo Antônio do Machado (1871); Estrada de Lambaria a Santo Antônio do Machado (1871); Estrada de Campanha a Águas Virtuosas (1871); Ponte do Paraibuna (1843-1844); Ponte sobre o Rio Santa Bárbara (1867-1869); Ponte sobre o Rio São João em Montes Claros (1885); Ponte sobre o Rio São João em Pitangui (1887).

${ }^{7}$ Mineradora Central Oeste, Mata, Sudeste, Sul Central e Intermediária de Pitangui-Tamanduá integram as regiões de "nível alto de desenvolvimento econômico". Ao lado delas, também se encontra a região de Diamantina. A região de nível alto de desenvolvimento econômico concentrava, em 1830, 66,7\% da população (487.669 indivíduos) e, em 1870, 59,7\% (1.243.838 indivíduos). As demais regiões, que totalizam 11 conforme regionalização de Godoy (1996) e Paiva e Godoy (2002), se distribuem em dois outros grupos de desenvolvimento: nível baixo de desenvolvimento econômico; e nível médio de desenvolvimento econômico.

${ }^{8}$ A respeito do conceito dos níveis de desenvolvimento econômico regionais e os respectivos indicadores, ver Paiva (1996, p. 95-96; 111-112).

${ }^{9}$ Sobre o impacto do arranjo institucional, Ato Adicional (1834), na constituição do aparato fiscal de Minas Gerais, dentro do qual as estradas e pontes exerceram relevante função para geração de divisas para os cofres públicos, ver Cravo (2013, p. 135-140).
} 


\section{Regionalização da Província de Minas Gerais}

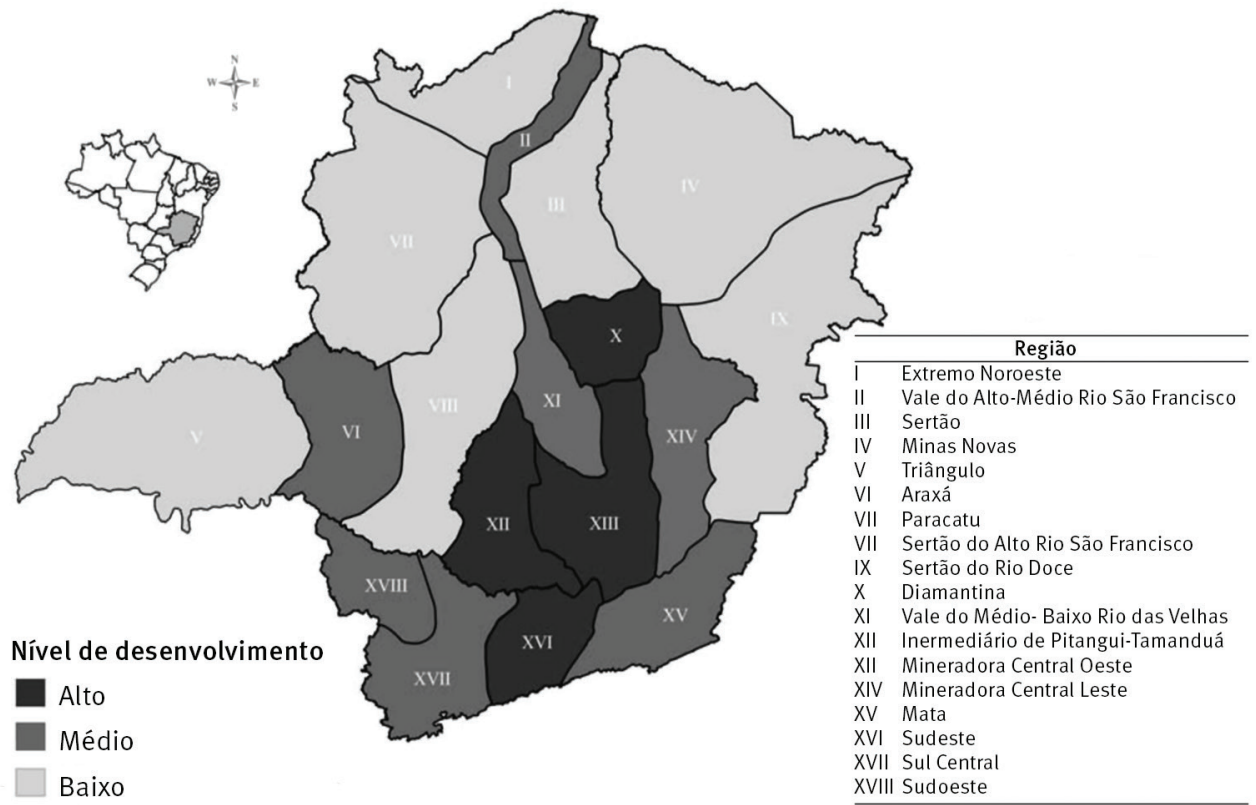

Fonte: IBGE. Malha Municipal do Brasil, 1997. Diretoria de Geociências. Departamento de Cartografia. GODOY (1996).

TABELA 1

Número de registros de trabalhadores, segunda a obra viária Regiões da província de Minas Gerais - 1835-1887

\begin{tabular}{llrr}
\hline \multicolumn{1}{c}{ Obra viária } & \multicolumn{1}{c}{ Região } & N & \% \\
\hline Estrada entre Mariana e São Caetano & Mineradora Central Oeste & 12 & 0,4 \\
Estrada em direção a Queluz & Mineradora Central Oeste & 14 & 0,4 \\
Estrada de São Sebastião a São Caetano & Mineradora Central Oeste & 17 & 0,5 \\
Estrada de São Caetano para Furquim & Mineradora Central Oeste & 17 & 0,5 \\
Estrada de Lambari a Santo Antônio do Machado & Sul Central & 23 & 0,7 \\
Estrada de Campanha a Águas Virtuosas & Sul Central & 31 & 0,9 \\
Ponte sobre o Rio São João em Pitangui & Intermediária de Pitangui-Tamanduá & 37 & 1,1 \\
Estrada de Campanha a Santo Antônio do Machado & Sul Central & 87 & 2,6 \\
Ponte sobre o Rio São João em Montes Claros & Sertão & 105 & 3,2 \\
Estrada de Lavrinhas & Mineradora Central Oeste & 148 & 4,5 \\
Ponte sobre o Rio Santa Bárbara & Mineradora Central Oeste & 272 & 8,2 \\
Ponte do Paraibuna & Mata & 456 & 13,8 \\
Estrada de Juiz de Fora a Barbacena & Mata e Sudeste & 803 & 24,3 \\
Estrada do Paraibuna & Mata & 1.278 \\
Total & & 38,7 \\
\hline
\end{tabular}

Fonte: Arquivo Público Mineiro (APM), OP 3/6, Caixa 4, doc. 02-40; 02-62; 02-79; 02-105; 02-131; OP 3/6, Caixa 11, doc. 11-44; 11-45; 11-46; OP 3/6, Caixa 41, doc. 21-07; 21-14; 21-21; 21-25; 21-33; 21-37; 21-40; 21-43; 21-47; 21-58; 21-62; 21-70; PP 1/46, Caixa 10, doc. 45-01; 45-02; 45-03; 45-04; PP 1/46, Caixa 19, doc. 07-02; 07-03; 07-04; OP 3/5, Caixa 10, doc. 01-01; 07-01; 10-01; OP 3/5, Caixa 4, doc. 05-01; 09-01; 32-01; 32-02; 32-03; OP 3/6, Caixa 49, doc. 18-54; 18-61; 18-67; 18-77; 18-81; 18-87; 18-91; 18-98; 18-105; 18-116; 18-124; 18-131; 18-144; 18-147; 18-154; 18-157; 18-171; 18-186; OP 3/6, Caixa 50, doc. 23-28; 23-32; 23-36; OP 3/6, Caixa 50, doc. 27-26. 
Pretende-se relacionar a estrutura ocupacional e a condição social dos trabalhadores, em 1830 e 1880, considerando a dinâmica da escravidão em Minas Gerais (LIBBY, 1988; SLENES, 1988; PAIVA, 1996; MARTINS, 2002; PAIVA; GODOY, 2002; RODARTE, 2012).

É importante sublinhar que, entre 1832 e 1872, a taxa de crescimento da população livre de Minas Gerais era de $2,8 \%$ ao ano e a da população escrava correspondia a $0,8 \%$ ao ano. Como parte do Império, a população de Minas Gerais, em 1832, representava $16,6 \%$ da população do Brasil. Após quatro décadas, em 1872, a província possuía $20,6 \%$ da população brasileira. Em termos absolutos, a província de Minas Gerais, em 1832, contabilizava 848.197 habitantes (572.099 livres e 276.098 escravos), passando para 2.083.545 (1.705.419 livres e 378.126 escravos), em 1872 (RODARTE, 2012; PAIVA; GODOY; RODARTE, 2012).

Tendo em vista essa dinâmica populacional, pode-se refletir sobre a composição da condição social dos trabalhadores encontrados nas Listas Nominativas de Trabalhadores. Os designados como livres correspondiam a quase um terço dos indivíduos das listas e os escravizados representavam $48,1 \%$ dos trabalhadores. Há ainda que ressaltar os casos de não informação para condição social dos trabalhadores, que totalizam 19,4\% dos trabalhadores contidos nas listas.

TABELA 2

Distribuição dos trabalhadores registrados nas Listas Nominais de Trabalhadores, segundo condição social

Província de Minas Gerais - 1835-1887

\begin{tabular}{lcc}
\hline \multicolumn{1}{c}{ Condição social } & N & $\%$ \\
\hline Sem informação & 641 & 19,4 \\
Livre & 1.071 & 32,5 \\
Escravo & 1.588 & 48,1 \\
Total & 3.300 & 100,0 \\
\hline
\end{tabular}

Fonte: Arquivo Público Mineiro, APM, OP 3/6: Processos de Construção de Estradas e Pontes, caixas 2 a 28 e 32 a 57.

Tendo em vista que exercer determinado ofício é situar-se numa hierarquia social de uma sociedade escravista, os dados ganham significado especial, pois fogem de generalizações censitárias (HÉLIN, 1977). Em conjunto, listas nominais, ocupação e condição social ajudam a esclarecer sobre o modo como operavam em conjunto com outros fatores: status, variáveis demográficas, jornal pago pelo dia de trabalho, tempo de trabalho e a mobilidade geográfica e econômica dos trabalhadores (CRAVO; GODOY, 2019).

Observa-se o significativo número de indivíduos livres e escravizados dedicados aos trabalhos braçais. As listas também mostram a concentração de escravizados em duas ocupações: artífices em pedra e cal e artífices em madeira (Tabela 3).

Chama a atenção que os livres concentravam-se nas ocupações trabalhadores braçais, artífices em madeira e artífices em pedra e cal. De modo semelhante aos livres, eram nessas mesmas atividades manuais e mecânicas que também predominavam os escravizados. 
TABELA 3

Distribuição dos trabalhadores registrados nas Listas Nominais de Trabalhadores, por condição social, segundo atividades manuais e mecânicas

\begin{tabular}{|c|c|c|c|c|c|c|}
\hline \multirow{2}{*}{ Atividades manuais e mecânicas } & \multicolumn{2}{|c|}{ Livres } & \multicolumn{2}{|c|}{ Escravos } & \multicolumn{2}{|c|}{ Total } \\
\hline & $\mathrm{N}$ & $\%$ & $\mathrm{~N}$ & $\%$ & $\mathrm{~N}$ & $\%$ \\
\hline Funções de coordenação ou administrativas e de controle (1) & 106 & 100,0 & & & 106 & 100,0 \\
\hline Artífices em madeira (2) & 150 & 59,0 & 104 & 40,9 & 254 & 100,0 \\
\hline Artífices em metais (3) & 27 & 58,7 & 19 & 41,3 & 46 & 100,0 \\
\hline Artífices em pedra e cal (4) & 137 & 50,1 & 136 & 49,8 & 273 & 100,0 \\
\hline Artífices em pedra (5) & 13 & 41,9 & 18 & 58,1 & 31 & 100,0 \\
\hline Trabalhadores não qualificados (braçais) & 1.235 & 47,7 & 1.355 & 52,3 & 2.590 & 100,0 \\
\hline Total & 1.668 & & 1.632 & & 3.300 & 100,0 \\
\hline
\end{tabular}

Fonte: Arquivo Público Mineiro, APM, OP 3/6: Processos de Construção de Estradas e Pontes, caixas 2 a 28 e 32 a 57.

(1) Funções de coordenação: apontador, administrador, condutor de trabalhos, feitor.

(2) Artífices em madeira: carpinteiro (mestre, contramestre, aprendiz, ajudante, oficial), serrador, carapina, carvoeiro.

(3) Artífices em metais: mestre ferreiro, oficial ferreiro e broqueiro.

(4) Artífices em pedra e cal: pedreiro (oficial, mestre, aprendiz, ajudante).

(5) Artífices em pedra: calceteiro, cavouqueiro.

Os indicadores da estrutura ocupacional são relevantes quando trazem à tona a presença de escravizados especializados em atividades em metais, como a de ferreiro. ${ }^{10}$ No caso da ocupação de trabalhadores braçais, as porcentagens de livres e escravos são surpreendentemente próximas.

Aspecto de grande interesse refere-se à disseminação do sistema de aluguel de escravizados, provavelmente, um dos componentes de maior importância para o entendimento da presença de cativos em obras públicas viárias. Nota-se que a dimensão do aluguel de escravos revela-se extremamente lucrativa. ${ }^{11}$ Recentes pesquisas indicam que as estimativas da taxa de retorno bruto anual nas obras públicas viárias superaram as taxas obtidas com aluguel nas atividades de extração mineral em Minas Gerais. No setor de extração mineral, entre 1800 e 1867, as taxas de retorno bruto anual com o sistema de aluguel oscilaram entre $18,0 \%$ e 24,3\% (LIBBY, 1984, p. 95; BERGAD, 2004, p. 286; 360 363; CRAVO, 2019, p. 175). Com base nas listas nominais de obras viárias, em especial das construções situadas na Mata mineira (Listas Nominais de Trabalhadores da Ponte do Paraibuna e Estrada da Corte), as estimativas das taxas de retorno bruto anual no sistema de aluguel de cativos alcançaram $38,3 \%$, em 1873 , e registraram estimativa de $57,7 \%$, em 1843 e 1844 (CRAVO, 2019; CRAVO; GODOY, 2019). Portanto, as taxas obtidas nas construções viárias superavam as taxas de retorno bruto anual do sistema de aluguel estimadas para o setor de extração mineral, o que é indício expressivo da lucratividade do aluguel de escravos em obras públicas, aspecto ainda pouco explorado pela historiografia (LIBBY, 1984; BERGAD, 2004; CRAVO, 2019; CRAVO; GODOY, 2019).

\footnotetext{
$\overline{10}$ Os escravizados não estão presentes apenas nas "funções de coordenação ou administrativas e de controle".

${ }^{11}$ Sobre a negociação, ajustamento e favorecimento aos donos de escravos na dinâmica do sistema de aluguel, bem como sobre a participação de proprietários escravistas com mais de 100 cativos e cafeicultores da Mata mineira no sistema de aluguel de obras viárias, ver Cravo e Godoy (2019).
} 
Além disso, salienta-se que, com base nos registros nominais dos trabalhadores, pode-se identificar o nome e o gênero dos proprietários escravistas que alugaram seus cativos. Eles totalizam 88 proprietários de escravos, sendo 76 do sexo masculino e 12 do feminino, o que indica que mulheres proprietárias de escravos se valeram dos lucros oriundos do sistema de aluguel.

\section{Considerações finais}

Os resultados trazem subsídios ao entendimento do papel representado não apenas pelo sistema de aluguel no escravismo, mas também da condição social dos trabalhadores e suas ocupações. Os resultados apresentados, por um lado, conjugam esforço crítico em direção aos limites e virtualidades da série documental e, por outro, sublinham a potencialidade dos registros para a análise do processo histórico-social de formação do mercado de trabalho livre e escravo no Brasil.

Em contraste sobre a importância do sistema de aluguel de escravos para os modos de obtenção da liberdade e da mobilidade social em espaços urbanos das cidades brasileiras do século XIX (FRANK, 2004; CHALHOUB, 2011), os resultados mostram que pontes e estradas, distantes de adensamentos urbanos, foram locus da prática de locação de cativos, ocupação, especialização e divisão social do trabalho de livres e escravos. Os dados indicam que, embora predominem proprietários de escravos do sexo masculino, mulheres escravistas também destinaram seus cativos para o sistema de aluguel.

À luz desses dados, os resultados refletem o fato de que as listas nominais, ainda pouca exploradas, deslocam o holofote para além das ferrovias. Ademais, sublinha-se que outras inúmeras listas nominais inexploradas já foram mapeadas e encontram-se no Arquivo Público Mineiro, o que constitui agenda futura de pesquisa e incorporação de novos resultados, bem como ampliação da amostragem e aprofundamento da significação do universo laboral das obras viárias na estrutura econômica e demográfica da maior província escravista do Império do Brasil durante todo o século XIX.

\section{Referências}

ARQUIVO Público Mineiro (APM), OP 3/6: Processos de Construção de Estradas e Pontes, caixas 2 a 28 e 32 a 57.

BARBOSA, L. Tropas e ferrovias em uma província não-exportadora: Estado, elites regionais e as contradições da política dos transportes no início da modernização - Minas Gerais, 18351889. Tese (Doutorado) - Instituto de Filosofia e Ciências Sociais, Universidade Federal do Rio de Janeiro, Rio de Janeiro, 2011.

BARBOSA, L.; GODOY, M. Transportes, região e desenvolvimento econômico: a dinâmica da expansão da infra-estrutura viária na província de Minas Gerais, 1840-1889. Varia Historia, v. 30, n. 53, p. 461-486, 2014. 
BARBOSA, L.; GODOY, M. Uma outra modernização: transportes em uma província não exportadora - Minas Gerais, 1850-1870. Economia e Sociedade, Campinas, v. 17, n. 2, p. 331-358, 2008.

BARBOSA, L.; GODOY, M.; MENDES, P. Transporte e finanças públicas. In: GOULARTI FILHO, A.; QUEIROZ, P. R. C. (org.). Transporte e formação regional: contribuições à história dos transportes no Brasil. Dourados: Ed UFGD, 2011.

BERGAD, L. W. Escravidão e história econômica: demografia de Minas Gerais, 1720-1880. Bauru: Edusc, 2004.

CARVALHO, J. M. de. Escola de Minas de Ouro Preto. O peso da glória. 2. ed. Belo Horizonte: Editora UFMG, 2002.

CECHIN, J. A construção e operação das ferrovias no Brasil do século XIX. 130 f. Dissertação (Mestrado em Economia) - Instituto de Economia, Universidade Estadual de Campinas (IE/Unicamp), Campinas, 1978.

CHALHOUB, S. Visões da liberdade: uma história das últimas décadas da escravidão na Corte. São Paulo: Cia das Letras, 2011.

COLLECÇÃO das leis da Assembleia Legislativa de Minas Gerais de 1866. Ouro Preto: Tipografia de J.F. de Castro, 1867.

COLLECÇÃO das leis da Assembleia Legislativa de Minas Gerais de 1873. Ouro Preto: Tipografia de J.F. de Castro, 1874.

CRAVO, T. Construindo pontes e estradas no Brasil Império: engenheiros e trabalhadores nas Minas Gerais (1835-1889). São Paulo: Alameda, 2016.

CRAVO, T. Modernização esquecida, construindo pontes e estradas no Brasil Impérial: engenheiros e artífices em uma região exportadora de Minas Gerais (1850-1875). Almanack, n. 6, p. 133-151, 2013.

CRAVO, T. Sistema de aluguel de escravos em obras públicas viárias do Brasil Império. Revista Brasileira de História \& Ciências Sociais, v. 11, n. 22, p. 162-181, 2019.

CRAVO, T.; CONTERNO, P.; GODOY, M. Imigração internacional e contratos de trabalho no Império do Brasil. Almanack, n. 25, p. 1-34, 2020.

CRAVO, T.; GODOY, M. Estado, transportes e mercado de trabalho: livres, libertos e escravos em obras públicas da província de Minas Gerais nas décadas de 1830-1840. Revista de História USP, n. 178, p. 1-34, 2019.

FRANK, Z. Dutra's world: wealth and family in nineteenth-century Rio de Janeiro. Albuquerque: University of New Mexico Press, 2004.

GODOY, M. Intrépidos viajantes e a construção do espaço: uma proposta de regionalização para as Minas Gerais do século XIX. Belo Horizonte: Cedeplar/UFMG, 1996. (Texto para Discussão, n. 109).

HÉLIN, E. Profissão e estatuto social. In: MARCíLIO, M. L. (org.). Demografia histórica. São Paulo: Livraria Pioneira Editora, 1977.

KLEIN, H. The colored freedmen in Brazilian slave society. Journal of Social History, v. 3, n. 1, p. 30-52, 1969. 
KLEIN, H.; LUNA, F. Pessoas livres de cor numa sociedade escravocrata: São Paulo e Minas Gerais no início do século XIX. In: LUNA, F. V.; COSTA, I. del N. da; KLEIN, H. S. Escravismo em São Paulo e Minas Gerais. São Paulo: Edusp, 2009. p. 461-492.

LAMOUNIER, M. Ferrovias e mercado de trabalho no Brasil do século XIX. São Paulo: Editora da Universidade de São Paulo, 2012.

LIBBY, D. Transformação e trabalho em uma economia escravista. São Paulo: Ed. Brasiliense, 1988.

LIBBY, D. C. Trabalho escravo e capital estrangeiro no Brasil. O caso de Morro Velho. Belo Horizonte: Ed. Itatiaia, 1984.

MARTINS, J. Dicionário de artistas e artífices dos séculos XVIII e XIX em Minas Gerais. Rio de Janeiro: Instituto do Patrimônio Histórico e Artístico Nacional, v. 1 e 2, 1974.

MARTINS, R. A economia escravista de Minas Gerais no século XIX. Belo Horizonte: Cedeplar/ UFMG, 1982. (Texto para Discussão, n. 10).

MARTINS, R. Tesouro revelado. Revista do Arquivo Público Mineiro, Ano LI, n. 1, p. 80-103, 2015.

MARTINS, R. Minas e o tráfico de escravos no século XIX, outra vez. In: SZMERECSÁNYI, T.; LAPA, J. A. (org.). História econômica da Independência e do Império. 2. ed. São Paulo: Edusp, 2002. p. 99-130.

MELLO, P. C.; SLENES, R. W. Análise econômica da escravidão no Brasil. In: NEUHASS, P. (coord.). Economia brasileira: uma visão histórica. Rio de Janeiro: Editora Campus, 1980.

NAGAMINI, M. Engenharia e técnica de construções ferroviárias e portuárias no Império. In: VARGAS, M. (org.). História da técnica e da tecnologia no Brasil. São Paulo: Unesp-Centro Estadual de Educação Tecnológica Paula Souza, 1994.

PAIVA, C. População e economia nas Minas Gerais do século XIX. 229 f. Tese (Doutorado em História) - FFLCH, Universidade de São Paulo (USP), São Paulo, 1996.

PAIVA, C.; GODOY, M. Território de contrastes: economia e sociedade das Minas Gerais do século XIX. In: X SEMINÁRIO SOBRE ECONOMIA MINEIRA. Anais [...]. Diamantina: Cedeplar/UFMG, 2002.

PAIVA, C.; GODOY, M.; RODARTE, M. Publicação crítica do recenseamento geral do Império do Brasil de 1872. Belo Horizonte: Núcleo de Pesquisa em História Econômica e Demográfica (NPHED), 2012.

PINTO, L. M. da S. Diccionario da Lingua Brasileira. Ouro Preto: Typ. de Silva, 1832.

RODARTE, M. O trabalho do fogo: domicílios ou famílias do passado, Minas Gerais 1830. Belo Horizonte: Ed. UFMG, 2012.

SILVA, S. Expansão cafeeira e origens da indústria no Brasil. São Paulo: Ed. Alfa-Omega, 1976.

SLENES, R. W. Os múltiplos de porcos e diamantes: a economia escrava de Minas Gerais no século XIX. Estudos Econômicos, São Paulo, v. 18, n. 3, p. 449-495, 1988.

SOUZA, R. Se eles são livres ou escravos (1858-1863). Tese (Doutorado) - Instituto de Filosofia e Ciências Humanas, Universidade Estadual de Campinas (Unicamp), Campinas, 2013.

TELLES, P. C. da S. História da Engenharia no Brasil. Rio de Janeiro: Clavero, 1994. v. 1. 


\title{
Sobre 0 autor
}

Télio Cravo é pós-doutorando no Departamento de História da Universidade Federal de São Paulo (Unifesp), doutor em História pela Universidade Estadual de Campinas (Instituto de Economia/ Unicamp) e mestre em História Social pela Universidade de São Paulo (FFLCH/USP), com bolsa CNPq. Pesquisador-residente na Biblioteca Brasiliana Guita e José Mindlin da Universidade de São Paulo (BBM-USP), integrado ao projeto 3×22. Integra o grupo de pesquisa Estados e Nações nas Américas no "longo século XIX": história e historiografia, da Universidade Federal de São Paulo e também o Grupo de Estudos do Progresso da Tecnologia e Ciência da Universidade de São Paulo (USP). Pesquisador associado do Núcleo de Pesquisa em História Econômica e Demográfica do Cedeplar/Face, Universidade Federal de Minas Gerais (UFMG).

\section{Endereço para correspondência}

Departamento de História

Estrada do Caminho Velho, n. 333, Jd. Nova Cidade

07252-312 - Guarulhos-SP, Brasil

\begin{abstract}
Nominal list of workers: free people and slaves in the construction of bridges and roads in the Minas Gerais Province (1830-1880)
\end{abstract}

This article shows the preliminary findings of operation of nominal lists of workers employed in the construction of bridges and roads in the Minas Gerais province. It emphasizes the occupation and social conditions of workers, as well as the slave rental system. In the 19th century, Minas Gerais held a prominent position in the national scene, especially due to its demographic and economic dynamism. It presented a population growth rate above the average in Brazil, maintained the largest slave system in the country. This article presents the results concerning 3,300 nominal lists of workers.

Keywords: Occupational structure. Free and slaves. Nominal lists. Workers. Minas Gerais.

\section{Resumen}

Lista nominal de trabajadores: esclavos y libres en la construcción de puentes y carreteras en la provincia de Minas Gerais (1830-1880)

Este artículo presenta los resultados preliminares de la exploración de las listas nominales de trabajadores empleados en la construcción de puentes y carreteras en la provincia de Minas Gerais. Se enfatiza en la ocupación y el estatus social, así como en el sistema de alquiler de esclavos. En el siglo XIX, Minas Gerais ocupó un lugar destacado en el panorama nacional, sobre todo por su dinamismo demográfico y económico. Presentó una tasa de crecimiento poblacional superior al promedio de Brasil y mantuvo el sistema esclavista más grande del país. En esta comunicación enumeramos resultados referentes a 3300 registros nominales.

Palabras clave: Estructura ocupacional. Libres y esclavos. Listas nominales. Trabajadores. Minas Gerais. 